\title{
Multistage CC-CV Charge Method for Li-Ion Battery
}

\author{
Xiaogang Wu, ${ }^{1}$ Chen Hu, ${ }^{1}$ Jiuyu Du, ${ }^{2}$ and Jinlei Sun ${ }^{3}$ \\ ${ }^{1}$ College of Electrical and Electronic Engineering, Harbin University of Science and Technology, Xue Fu Road 52, Harbin 150080, China \\ ${ }^{2}$ State Key Laboratory of Automotive Safety and Energy, Tsinghua University, Beijing, China \\ ${ }^{3}$ School of Electrical Engineering and Automation, Harbin Institute of Technology, Harbin, China
}

Correspondence should be addressed to Xiaogang Wu; xgwu@hrbust.edu.cn

Received 18 August 2015; Revised 26 September 2015; Accepted 28 September 2015

Academic Editor: Xiaosong Hu

Copyright (C) 2015 Xiaogang Wu et al. This is an open access article distributed under the Creative Commons Attribution License, which permits unrestricted use, distribution, and reproduction in any medium, provided the original work is properly cited.

\begin{abstract}
Charging the Li-ion battery with constant current and constant voltage (CC-CV) strategy at $-10^{\circ} \mathrm{C}$ can only reach $48.47 \%$ of the normal capacity. To improve the poor charging characteristic at low temperature, the working principle of charging battery at low temperature is analyzed using electrochemical model and first-order RC equivalent circuit model; moreover, the multistage CC$\mathrm{CV}$ strategy is proposed. In the proposed multistage CC-CV strategy, the charging current is decreased to extend the charging process when terminal voltage reaches the charging cut-off voltage. The charging results of multistage CC-CV strategy are obtained at $25^{\circ} \mathrm{C}, 0^{\circ} \mathrm{C}$, and $-10^{\circ} \mathrm{C}$, compared with the results of CC-CV and two-stage CC-CC strategies. The comparison results show that, at the target temperatures, the charging capacities are increased with multistage CC-CV strategy and it is notable that the charging capacity can reach $85.32 \%$ of the nominal capacity at $-10^{\circ} \mathrm{C}$; also, the charging time is decreased.
\end{abstract}

\section{Introduction}

With the advantages of zero pollution, high energy efficiency, and pluralistic energy sources, electric vehicle (EV) has been the new development point of motor industry [1-3]. Liion battery has been widely used in EV for its high energy density, long cycle life, and high safety level [4]. But the battery technology still cannot meet the EV demand of long travel distance, fast capacity recovery, and low temperature utilization [5]. At low temperature, battery chemical activity decreases, resistance increases, and capacity is decreased. Charging process is more difficult than the discharging process at low temperature $[6,7]$.

Much work has been done on charging strategies in recent years. In [8] a three-step charging method for Ni/MH battery was proposed to obtain the rapid charge. In [9], an optimum current charging strategy based on the boundary charging current curves was proposed. The boundary charging current curves were obtained by analysis of temperature rise and polarization voltage in charging process. The charging period was decreased and capacity was increased with the strategy. Reference [10] proposed a duty-varied voltage charging strategy that can detect and dynamically track the suitable duty of the charging pulse. Compared with conventional
CC-CV strategy, the charging speed was increased by $14 \%$, and charging efficiency was increased by $3.4 \%$. Reference [11] constructed a SOC estimation model and the CCCV charging process was controlled by battery SOC. The charging capacity can be monitored to gain a higher level charging degree and avoid being overcharged. In [12], an Ant Colony System algorithm was used to select the optimum charging current among five charging states and the charging time was decreased and battery cycle life was extended by $25 \%$. In [13], a Taguchi-based algorithm was used to obtain rapid charge. With the charging strategy, the battery capacity could reach to $75 \%$ in $40 \mathrm{~min}$. In [14], a constantpolarization-based fuzzy-control charging method was proposed to adapt charging current acceptance with battery SOC stages. The charging strategy could shorten charging time with no obvious temperature rise. Ruan et al. and Zhao et al. $[15,16]$ studied the temperature characteristic of charging and discharging process. The temperature increased more in discharging process compared to the temperature increase in charging process. The pulse charging/discharging process was added before charging process so the battery could be preheated. The battery could start charging process at relatively high temperature and charging capacity was increased at low temperature. 
TABLE 1: Equipment parameters.

\begin{tabular}{lcc}
\hline \multirow{3}{*}{ Battery equipment } & Maximum test current & $20 \mathrm{~A}$ \\
& Maximum test voltage & $5 \mathrm{~V}$ \\
& Test accuracy & $0.1 \%$ \\
\hline \multirow{3}{*}{ Temperature chamber } & Maximum temperature & $150^{\circ} \mathrm{C}$ \\
& Minimum temperature & $-40^{\circ} \mathrm{C}$ \\
& Temperature tolerance & $0.01^{\circ} \mathrm{C}$ \\
\hline
\end{tabular}

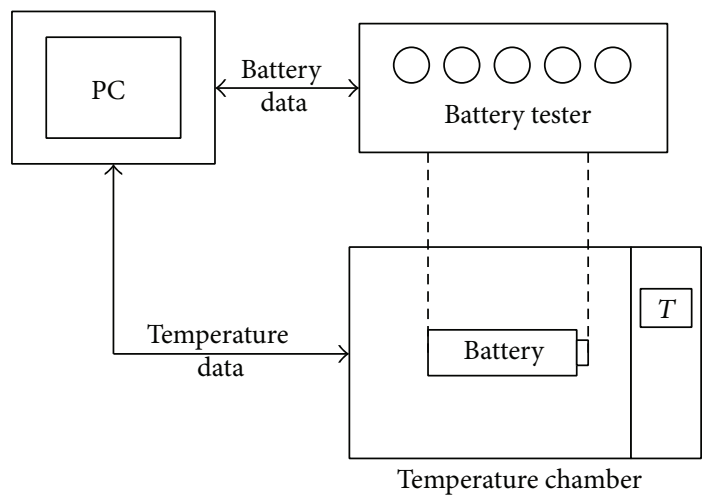

FIGURE 1: Experimental setup.

All the charging strategies increase the battery charging characteristic at different degrees proposed in [8-14]. But the charging performance at low temperature is not considered. Although the preheating charging strategy at low temperature proposed in $[15,16]$ can increase the charging capacity, the self-preheating process costs too much time and cannot work at low SOC condition. This paper analyzes the charging characteristic of a Li-ion battery at different temperature, uses electrochemical model and first-order $R C$ equivalent circuit model to analyze the bad low temperature characteristic of Li-ion battery in theory, and proposes a multistage CC-CV strategy. The multistage CC-CV strategy is compared with $\mathrm{CC}-\mathrm{CV}$ and two-stage $\mathrm{CC}-\mathrm{CV}$ strategies at $25^{\circ} \mathrm{C}, 0^{\circ} \mathrm{C}$, and $-10^{\circ} \mathrm{C}$.

\section{Experimental}

2.1. Battery and Equipment. The battery used is 18650 cylindrical Li-ion battery with normal capacity of $1.37 \mathrm{Ah}$, a normal voltage of $3.2 \mathrm{~V}$, and a cut-off voltage of $3.6 \mathrm{~V}$. The maximum charging and discharging rates are $1 \mathrm{C}$ and $2 \mathrm{C}$, respectively. The positive electrode material is $\mathrm{LiFePO}_{4}$, and negative electrode material is $\mathrm{LiC}_{6}$. The battery tester is $\mathrm{LD}$ battery tester with 8 test channels and the test process can be programmed and monitored by computer. The battery was tested in a temperature chamber to ensure the temperature parameter to be constant. The detailed parameters of battery tester and temperature chamber are shown in Table 1. The experimental setup can be described as in Figure 1.

2.2. Experimental Process. The battery charging strategies tested in experiments were CC-CV, two-stage CC-CV, and multistage CC-CV. The test temperature points were $25^{\circ} \mathrm{C}$, $0^{\circ} \mathrm{C}$, and $-10^{\circ} \mathrm{C}$. The charging strategies are explained as follows.

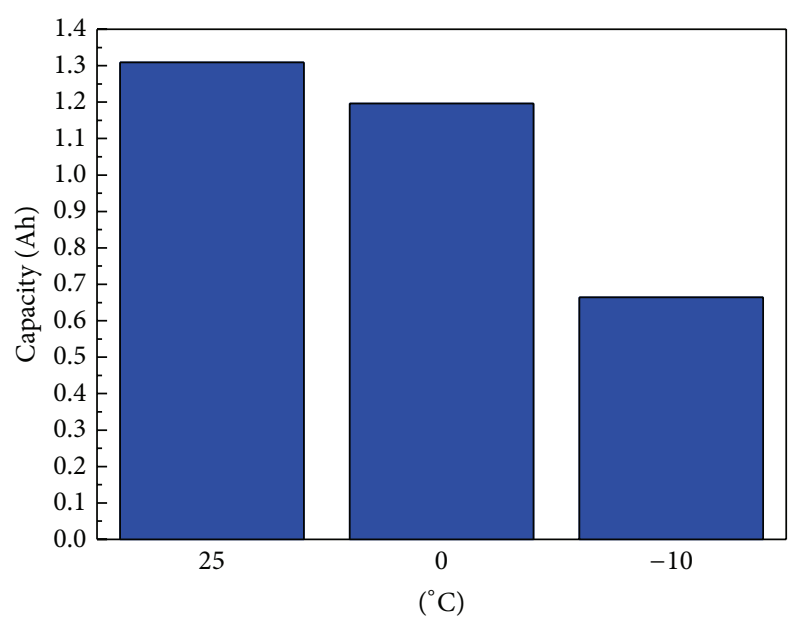

FIGURE 2: CC-CV strategy charging capacities at different temperature.

For the CC-CV strategy, the constant current process was charging at $0.3 \mathrm{C}$ to the cut-off voltage of $3.6 \mathrm{~V}$ and the constant voltage process was charging at $3.6 \mathrm{~V}$ for $5 \mathrm{~min}$.

For the two-stage CC-CV strategy, the first constant current process was charging at $1 \mathrm{C}$ to the cut-off voltage of $3.6 \mathrm{~V}$. Then in the second constant current process, the charging current was decreased to $0.5 \mathrm{C}$. Since the charging current was decreased, the terminal voltage was decreased below $3.6 \mathrm{~V}$ allowing the constant current process to be extended, until the terminal voltage reached the cut-off voltage once again. The constant voltage process was charging at $3.6 \mathrm{~V}$ for $5 \mathrm{~min}$ [17].

For the multistage CC-CV strategy, the constant current process was divided into ten stages. The maximum and minimum rates were $1 \mathrm{C}$ and $0.1 \mathrm{C}$, respectively, and the charging current was decreased by $0.1 \mathrm{C}$ when terminal voltage reached the cut-off voltage. The constant voltage process was charging at $3.6 \mathrm{~V}$ for $5 \mathrm{~min}$.

\section{Charging Characteristic of Battery at Low Temperature}

3.1. Charging Capacity Characteristic at Different Temperature. The selected battery was charged by CC-CV strategy at $25^{\circ} \mathrm{C}, 0^{\circ} \mathrm{C}$, and $-10^{\circ} \mathrm{C}$ to obtain the charging capacity characteristic at low temperature. Before every charging process at different temperature, the battery was discharged empty at $25^{\circ} \mathrm{C}$ and kept for six hours to ensure the whole battery temperature to be uniform. As shown in Figure 2, the charging capacities at $25^{\circ} \mathrm{C}, 0^{\circ} \mathrm{C}$, and $-10^{\circ} \mathrm{C}$ are $1.309 \mathrm{Ah}$, $1.196 \mathrm{Ah}$, and $0.664 \mathrm{Ah}$, respectively. The charging capacity is decreased by $8.6 \%$ at $0^{\circ} \mathrm{C}$ and $49.3 \%$ at $-10^{\circ} \mathrm{C}$ compared with that at $25^{\circ} \mathrm{C}$. The charging capacity has a great decrease at $-10^{\circ} \mathrm{C}$.

3.2. OCV Characteristic at Different Temperature. The battery was tested by hybrid pulse power characteristic (HPPC) rule that is detailed in "Freedom CAR Battery Test Manual" [18] to obtain OCV, ohmic resistance $\left(R_{r}\right)$, and polarization 


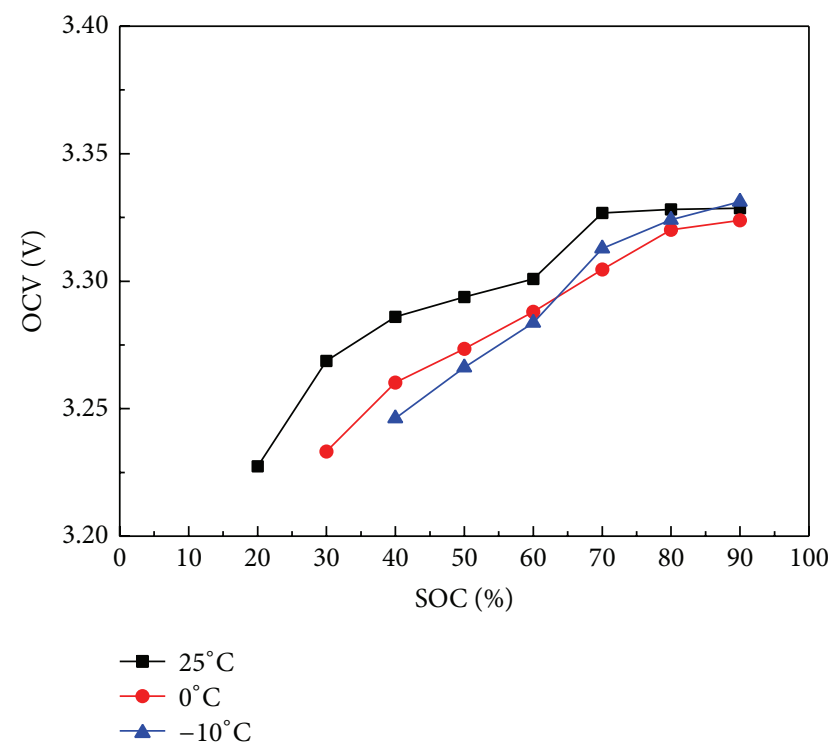

Figure 3: OCV curves at different temperature.

resistance $\left(R_{p}\right)$. SOC can be calculated by the following formula:

$$
\mathrm{SOC}=\mathrm{SOC}_{0}-\frac{1}{\mathrm{AHC}} \int_{0}^{t} i d \tau,
$$

where $\mathrm{SOC}_{0}$ is the initial SOC of the battery, AHC is the normal capacity of the battery at $25^{\circ} \mathrm{C}$, and $i$ is the discharge (positive $i$ ) or charge (negative $i$ ) current. As the OCV curves shown in Figure 3, the OCV reflects increasing tendency with temperature decreasing and the difference of OCV at different temperature is relatively more obvious at low SOC.

3.3. $R_{r}$ and $R_{p}$ Characteristic at Different Temperature. As shown in Figures 4 and 5, both $R_{r}$ and $R_{p}$ increase with temperature decreasing. $R_{r}$ remains steady with SOC increasing, and the increase is nearly $258 \%$ at $-10^{\circ} \mathrm{C} . R_{p}$ increases with SOC increasing and temperature decreasing, and the maximum increase in $R_{p}$ is nearly $257 \%$ at $-10^{\circ} \mathrm{C}$ with $90 \%$ of SOC.

\section{Electrochemical and First-Order $R C$ Equivalent Circuit Model}

4.1. Electrochemical Li-Ion Battery Model. Doyle et al. have proposed the porous electrode theory for the analysis of electrochemical process of Li-ion battery [19]. The onedimensional geometry consists of negative/positive current collector, negative/positive electrodes, and separator. The negative current collector material is copper, and positive current collector material is aluminum. The positive electrode active material is $\mathrm{LiFePO}_{4}$, and negative electrode active material is $\mathrm{LiC}_{6}$. The separator is polyolefin porous membrane. The electrolyte is lithium salt dissolved in $1: 1$ or 2:1 liquid mixture of ethylene carbonate (EC) and dimethyl carbonate (DMC). The one-dimensional geometry example

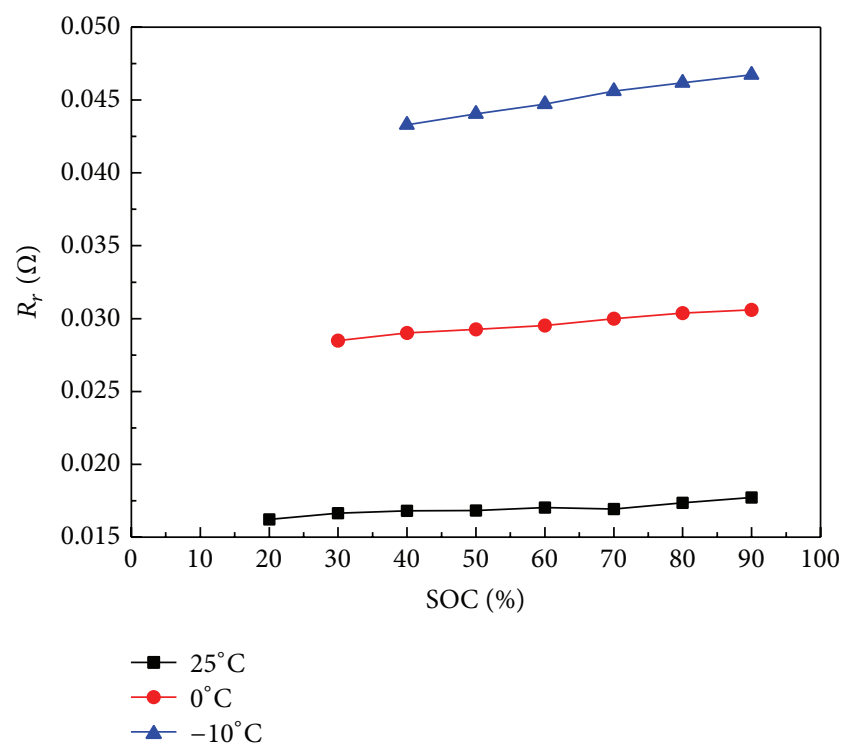

Figure 4: $R_{r}$ curves at different temperature.

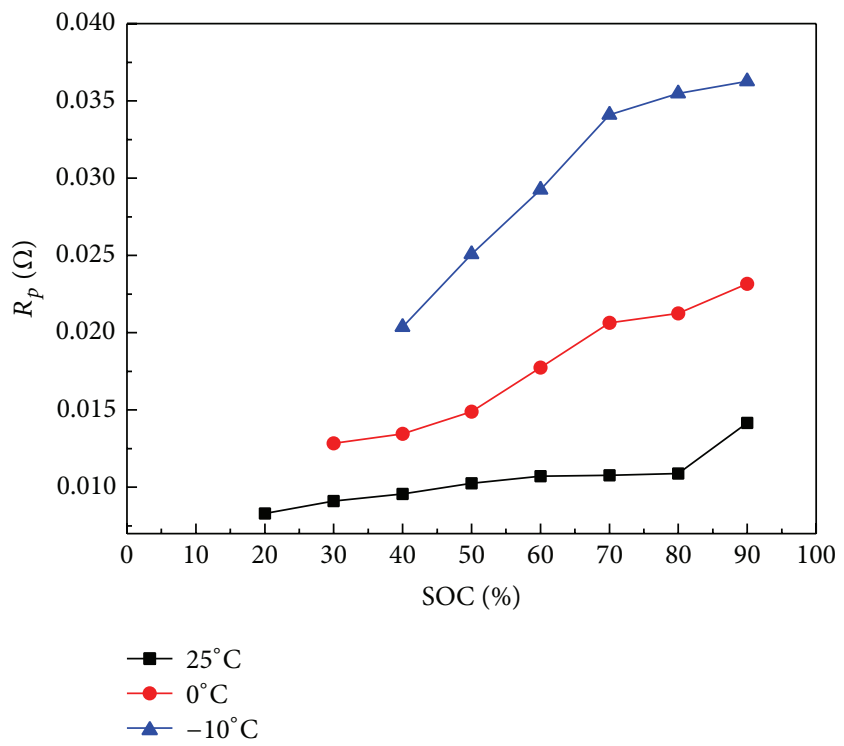

Figure 5: $R_{p}$ curves at different temperature.

of charging process is shown in Figure 6 [20] and the charging chemical equation is

Negative Electrode: $\mathrm{Li}_{x-z} C_{6}+z \mathrm{Li}^{+}+z e^{-}$

$$
\stackrel{\text { Charge }}{\longrightarrow} \mathrm{Li}_{x} C_{6} \text {, }
$$

Positive Electrode: $\mathrm{Li}_{y} \mathrm{FePO}_{4}$

$$
\stackrel{\text { Charge }}{\longrightarrow} \mathrm{Li}_{y-z} \mathrm{FePO}_{4}+z \mathrm{Li}^{+}+z e^{-}
$$

In the charging process, the electrons move from the positive electrode to the negative electrode through the external circuit, and $\mathrm{Li}^{+}$moves from the positive electrode to the negative electrode through the separator in electrolyte. 


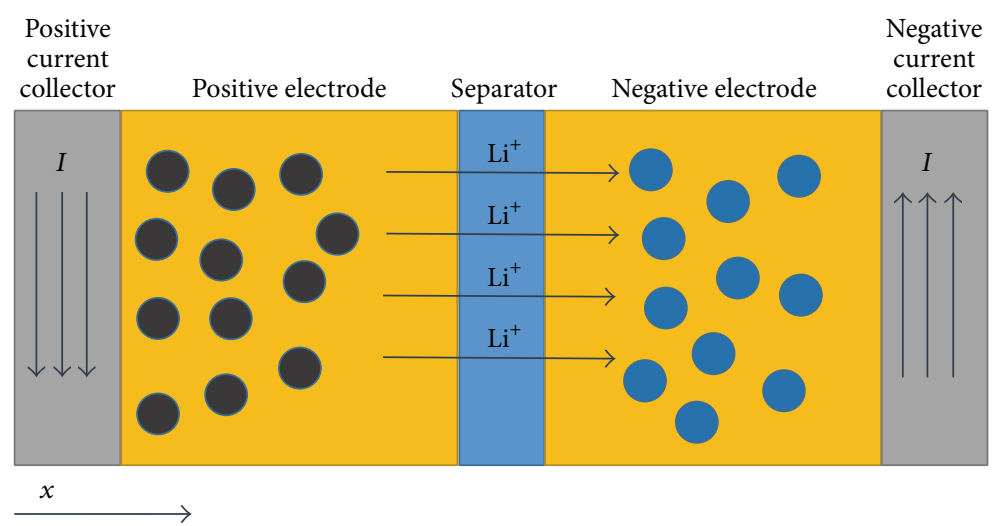

FIGURE 6: One-dimensional geometry example of charging process.

As the charging process is a chemical reaction, the reaction characteristic is influenced by concentration and $\mathrm{Li}^{+}$diffusion. The Li-ion concentration in electrolyte phase changes with time and can be described by Fick's second law along the $x$-coordinate shown in Figure 6 [21]:

$$
\frac{\partial C_{e}}{\partial t}=\frac{\partial}{\partial x}\left(D_{e} \frac{\partial C_{e}}{\partial x}\right)+\frac{1-t_{+}^{0}}{F} j^{\mathrm{Li}},
$$

where $C_{e}$ is the concentration of Li-ion in electrolyte phase, $D_{e}$ is $\mathrm{Li}^{+}$diffusion coefficient in electrolyte phase, $t_{+}^{0}$ is the transference number of lithium ions with respect to the velocity of the solvent, $F$ is Faraday constant, and $j^{\mathrm{Li}}$ is charging transfer current density.

The distribution of Li-ion in solid state phase is also described by Fick's second law of diffusion in polar coordinates [21]:

$$
\frac{\partial C_{s}}{d t}=\frac{D_{s}}{r^{2}} \frac{\partial}{\partial r}\left(r^{2} \frac{C_{s}}{\partial r}\right)
$$

where $C_{s}$ is the concentration of Li-ion in solid, $D_{s}$ is the $\mathrm{Li}^{+}$ diffusion coefficient in solid state phase, and $r$ is radius of spherical particle.

The Arrhenius formula shows the $\mathrm{Li}^{+}$diffusion coefficient $D_{s}$ in solid state phase as shown below [21]:

$$
D_{s}(T)=D_{\text {ref }} \exp \left[\frac{E_{a D}}{R}\left(\frac{1}{T_{\text {ref }}}-\frac{1}{T}\right)\right],
$$

where $E_{a D}$ is the activation energy for diffusion. $R$ is the universal gas constant, $D_{\text {ref }}$ is the reference diffusion coefficient at $T_{\text {ref }}, T_{\text {ref }}$ is the reference temperature, and $T$ is the temperature. Formula (5) shows that the diffusion coefficient decreases with the temperature decreasing. Reference [14] indicates that the solid state phase diffusion polarization dominates the total polarization and the solid state phase polarization is increased with diffusion coefficient decreasing. The increase of polarization results in higher polarization voltage compared with that of normal temperature, the terminal voltage increasing space during constant current charging process is decreased, and the charging capacity will be decreased.
The charging transfer current density can be obtained using the following Butler-Volmer formula [20]:

$$
j^{\mathrm{Li}}=j_{0}\left\{\exp \left[\frac{\alpha_{a} F}{R T} \eta\right]-\exp \left[\frac{\alpha_{c} F}{R T} \eta\right]\right\},
$$

where $j_{0}$ is the exchange current density, $\alpha_{a}$ and $\alpha_{c}$ are the transfer coefficients of anode and cathode, and $\eta$ is the surface over potential, which can be obtained using the following formula [20]:

$$
\eta=\phi_{s}-\phi_{e}-U_{\mathrm{ocv}}
$$

where $\phi_{s}$ is the solid phase potential, $\phi_{e}$ is the electrolyte phase potential, and $U_{\text {ocv }}$ is the open circuit voltage.

$j_{0}$ can be described as shown below [20]:

$$
j_{0}=F k_{0} C_{e}^{\alpha_{a}}\left(C_{s, \max }-C_{s, \text { surf }}\right)^{\alpha_{a}} C_{s, \text { surf }}^{\alpha_{a}},
$$

where $k_{0}$ is the reaction rate coefficient, $C_{s, \max }$ is the maximum Li-ion concentration in the electrodes, and $C_{s, \text { surf }}$ is the $\mathrm{Li}$-ion concentration on the active particles surface.

$k_{0}$ can be obtained using the following formula [20]:

$$
k_{0}(T)=k_{0, \text { ref }} \exp \left[\frac{E_{a R}}{R}\left(\frac{1}{T_{\text {ref }}}-\frac{1}{T}\right)\right],
$$

where $E_{a r}$ is the reaction activation energy and $k_{o \text {,ref }}$ is the reaction rate coefficient at $T_{\text {ref }}$. With the temperature decreasing, reaction rate coefficient is decreased. As formula (7) shows, $k_{0}$ is decreased with temperature decreasing. The charging reaction is impeded for the reaction rate coefficient decreasing. As the parameter is time-invariant, the charging obstruction can be considered as a resistive process. The increase of impedance also results in the terminal voltage increase and the decrease of charging capacity.

The electrochemistry model analysis of the charging process at low temperature shows that the main obstruction consists of polarization and impedance increase. This increase can be analyzed by the equivalent circuit model, the polarization can be modeled by capacitance and resistance in parallel, and the impedance can be modeled by resistance. A first-order $R C$ equivalent circuit model is used in the next part. 


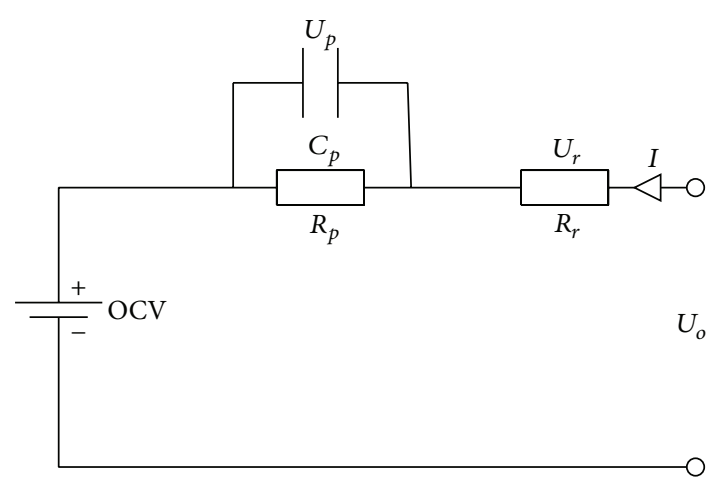

FIGURE 7: First-order $R C$ equivalent circuit model.

4.2. First-Order RC Equivalent Circuit Model. The first-order $R C$ equivalent circuit model is used to analyze the charging process $[21,22]$. As shown in Figure $7, R_{r}$ represents the ohmic resistance, $U_{r}$ is the voltage on $R_{r}, C_{p}$ and $R_{p}$, respectively, represent the polarization capacity and polarization resistance, $U_{p}$ is the voltage on $C_{p}$ and $R_{p}$, OCV is the open circuit voltage, $U_{o}$ is the terminal voltage, and $I$ is the charging current. The following formulas can be obtained:

$$
\begin{aligned}
C_{p} \frac{d u_{p}(t)}{d t}+\frac{u_{p}(t)}{R_{p}} & =i(t), \\
u_{0}(t) & =u_{\mathrm{ocv}}(t)+i(t) R_{r}+u_{p}(t) .
\end{aligned}
$$

With assumption of $i(0)=I$ and $u_{p}(0)=0$, the following can be obtained:

$$
\begin{aligned}
& u_{p}(t)=I R_{p}\left(1-e^{-t / \tau}\right), \\
& u_{0}(t)=u_{\mathrm{ocv}}(t)+I R_{r}+u_{p}(t),
\end{aligned}
$$

where $\tau=R_{p} C_{p}$.

It can be seen from formulas (10)-(11) that $U_{o}$ is determined by OCV, $R_{p}, R_{r}$, and $I$. As is mentioned above, OCV changes little with temperature decreasing, while $R_{r}$ and $R_{p}$ increase significantly with temperature decreasing. The increase of $R_{p}$ can be explained by the slow kinetics of electrochemical reaction influenced by temperature. The constant current process of CC-CV strategy is limited by cut-off voltage and the charging capacity mainly depends on the constant current process. At low temperature, $R_{r}$ and $R_{p}$ increase making $U_{r}$ and $U_{p}$ increase, and $U_{0}$ is higher than that at normal temperature. The cut-off voltage is reached earlier and the constant current process is stopped earlier [23]. The increasing of $R_{p}$ and $R_{r}$ depends on the battery design parameters and cannot be controlled during the charging process. The only parameter which can be controlled is the charging current. As proposed in [17], for a two-stage CC-CV strategy, the constant current charging process was divided into two stages. The first stage is charging battery with the maximum charging rate until the cut-off voltage is reached. The second stage charging current was decreased to half of the maximum charging rate, and the terminal voltage can be decreased to extend the constant

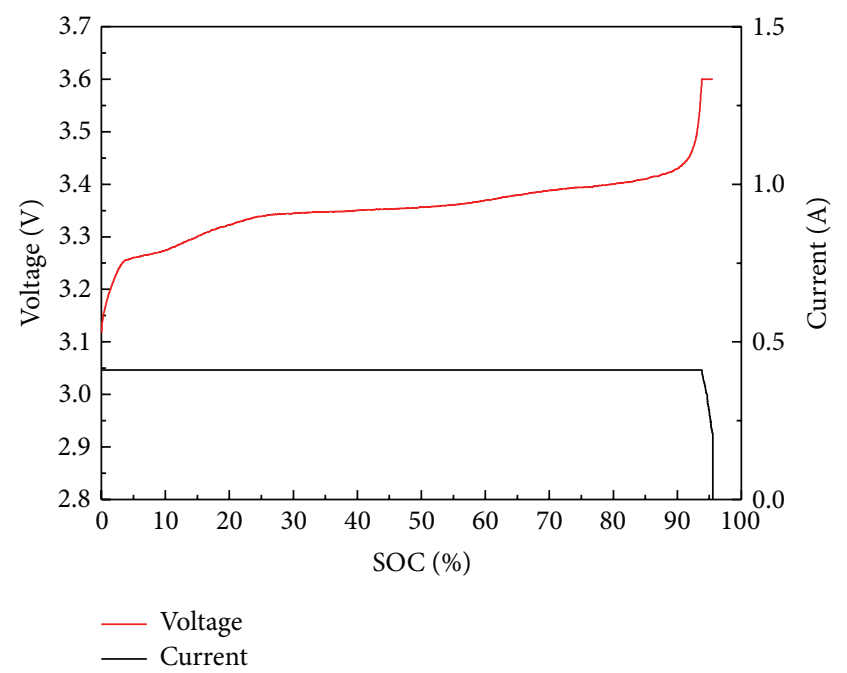

FIGURE 8: Charging curves of CC-CV strategy at $25^{\circ} \mathrm{C}$.

current charging process to increase capacity. According to the current decrease process of the two-stage CC-CV strategy, a multistage CC-CV strategy with more detailed current rates is proposed in this paper. Once the cut-off voltage is rapidly reached at a low temperature, the terminal voltage can be decreased with charging current decreasing, and the constant current charging process can be repeatedly extended to increase charging capacity. Meanwhile, the charging current is decreased from the maximum rate, and the multistage can automatically and degressively select the optimal charging current to use high charging rate as far as possible and shorten the charging period.

\section{Result and Discussion}

5.1. Different Charging Strategy Analysis at $25^{\circ} \mathrm{C}$. Figures 810 show the terminal voltage curves with different charging strategies at $25^{\circ} \mathrm{C}$. The terminal voltage of CC-CV strategy increases to $3.25 \mathrm{~V}$ at the low SOC range of $0 \%-10 \%$, while the terminal voltages of two-stage $\mathrm{CC}-\mathrm{CV}$ and multistage $\mathrm{CC}$ $\mathrm{CV}$ strategies increase to near $3.4 \mathrm{~V}$. The terminal voltage of CC-CV strategy increases to $3.4 \mathrm{~V}$ with SOC reaching $90 \%$ and has a huge increase to $3.6 \mathrm{~V}$ at the end of charging. The terminal voltages of two-stage $\mathrm{CC}-\mathrm{CV}$ and multistage CC-CV strategies increase to $3.6 \mathrm{~V}$ with SOC of $85 \%$. With current decreasing, the terminal voltage of two-stage CC-CV strategy decreases to $3.49 \mathrm{~V}$ and increases to $3.6 \mathrm{~V}$ again with SOC increasing of $7 \%$. Unlike two-stage CC-CV strategy, the terminal voltage of multistage $\mathrm{CC}-\mathrm{CV}$ strategy has more decreasing times to extend the charging SOC to a higher level.

Figure 11 shows the SOC curves of different charging strategies at $25^{\circ} \mathrm{C}$. The charging capacities of CC-CV, twostage $\mathrm{CC}-\mathrm{CV}$, and multistage $\mathrm{CC}-\mathrm{CV}$ charging strategies are 1.309 Ah, 1.299 Ah, and 1.368 Ah, respectively. The capacities of two-stage CC-CV and multi-CC-CV strategies are higher than that of CC-CV strategy for current decreasing process. The multi-CC-CV has the highest charging capacity because the current decrease process of multistage CC-CV strategy 


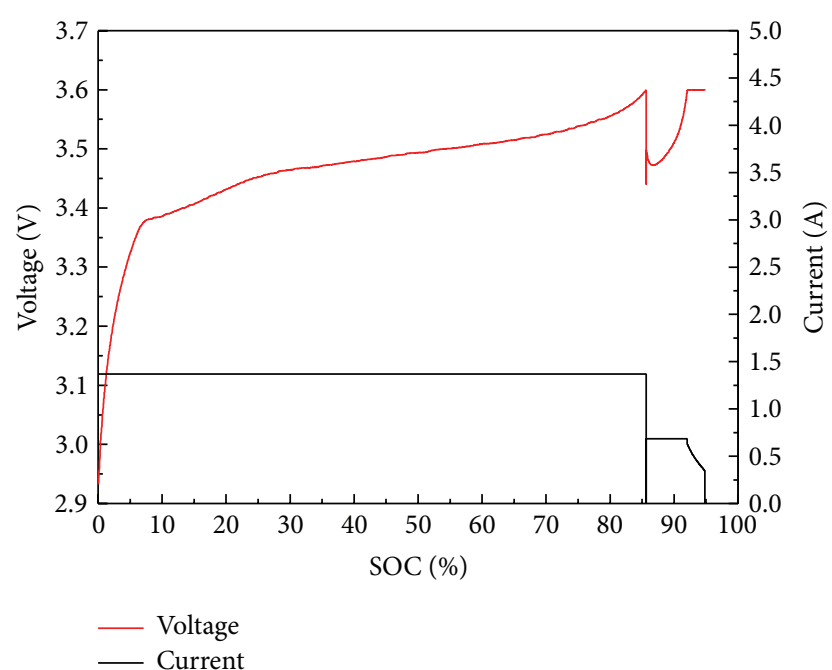

Figure 9: Charging curves of two-stage CC-CV strategy at $25^{\circ} \mathrm{C}$.

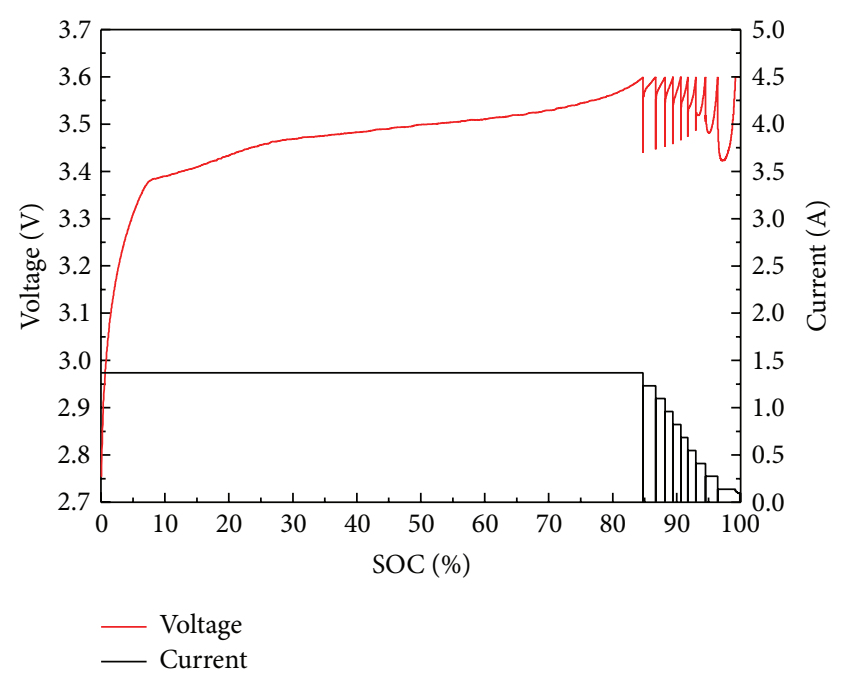

Figure 10: Charging curves of multistage CC-CV strategy at $25^{\circ} \mathrm{C}$.

has more gradients than two-stage CC-CV strategy. The charging periods of $\mathrm{CC}-\mathrm{CV}$, two-stage $\mathrm{CC}-\mathrm{CV}$, and multistage CC-CV charging strategies are $223 \mathrm{~min}, 67.4 \mathrm{~min}$, and $94.7 \mathrm{~min}$, respectively. It is obvious that the CC-CV charging strategy has the longest charging period for a low constant charging rate. Although the whole charging period of twostage CC-CV is shorter than that of the multistage CC-CV, multistage $\mathrm{CC}-\mathrm{CV}$ charging strategy has a larger charging capacity. The charging period of multistage CC-CV strategy is shorter than that of two-stage CC-CV strategy at the same charging SOC point $94.8 \%$.

5.2. Different Charging Strategy Analysis at $0^{\circ} \mathrm{C}$. As shown in Figure 12, unlike the terminal voltage at $25^{\circ} \mathrm{C}$, the terminal voltage of CC-CV strategy increases to $3.35 \mathrm{~V}$ at low SOC range of $0 \%-10 \%$. The terminal voltage increase slope during SOC range of $10 \%-80 \%$ is enhanced. The terminal voltage increase towards the cut-off voltage and sharp increase

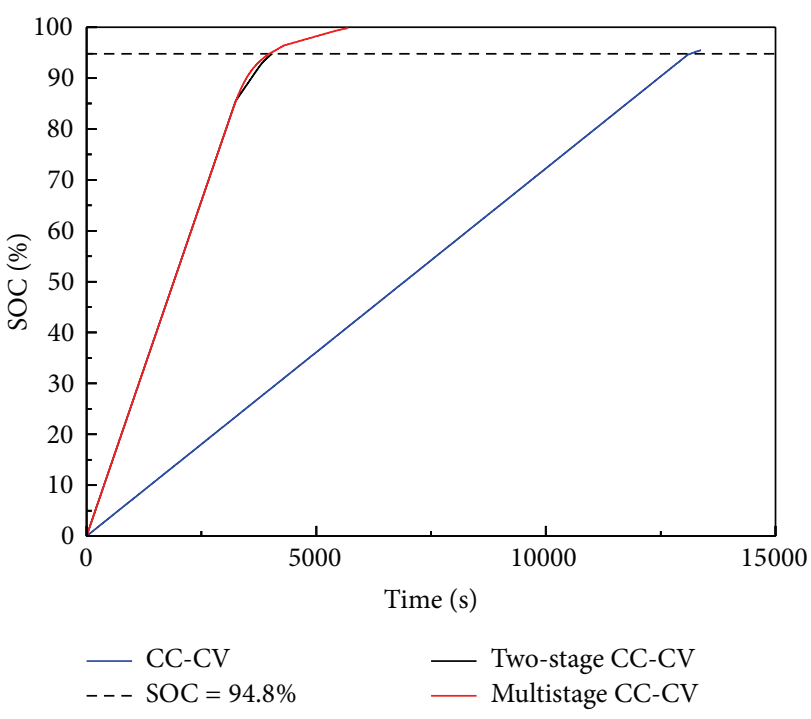

FIgURE 11: SOC curves of different charging strategies at $25^{\circ} \mathrm{C}$.

at $25^{\circ} \mathrm{C}$ with SOC range beyond $80 \%$ are vanished. The increase in terminal voltage indicates that the normal CC-CV charging process has been changed by the increase in internal resistance at low temperature.

As shown in Figures 13-14, the first charging stage of twostage CC-CV strategy does not last long before the cut-off voltage is reached for the increase in internal resistance and the high charging rate. The second charging stage decreases the charging current rate by $0.5 \mathrm{C}$, and the terminal voltage decreases by $0.23 \mathrm{~V}$ and keeps on increasing until the cut-off voltage is reached. Unlike the two-stage CC-CV strategy, the current decreases by $0.1 \mathrm{C}$ of the multistage $\mathrm{CC}-\mathrm{CV}$ strategy. The terminal voltages of $1 \mathrm{C}-0.7 \mathrm{C}$ constant current charging stages increase rapidly with SOC below $22 \%$. Terminal voltages of $0.6 \mathrm{C}-0.4 \mathrm{C}$ constant current charging stages increase slower with SOC between $22 \%$ and $73.4 \%$. Terminal voltages of $0.3 \mathrm{C}-0.1 \mathrm{C}$ constant current charging stages increase rapidly again with SOC beyond $73.4 \%$. The terminal voltage curve of multistage $\mathrm{CC}-\mathrm{CV}$ indicates that multistage $\mathrm{CC}-\mathrm{CV}$ strategy can automatically select the optimal charging current by cut-off voltage limiting and current decreasing.

The charging result at $0^{\circ} \mathrm{C}$ shows that the capacities of $\mathrm{CC}-\mathrm{CV}$, two-stage $\mathrm{CC}-\mathrm{CV}$, and multistage $\mathrm{CC}-\mathrm{CV}$ charging strategies are $1.196 \mathrm{Ah}, 0.758 \mathrm{Ah}$, and $1.246 \mathrm{Ah}$, respectively. Compared with the charging result at $25^{\circ} \mathrm{C}$, the charging capacities of CC-CV, two-stage CC-CV, and multistage CCCV charging strategies decrease by $8.2 \%, 39.5 \%$, and $8.9 \%$, respectively. As the main charging rate of two-stage $\mathrm{CC}-\mathrm{CV}$ strategy is $0.5 \mathrm{C}$ higher than $0.3 \mathrm{C}$ of CC-CV strategy and the charging rate does not decrease further, the two-stage CC-CV strategy has the largest decrease in charging capacity decrease at $0^{\circ} \mathrm{C}$. As multistage CC-CV strategy has $0.2 \mathrm{C}$ and $0.1 \mathrm{C}$ charging rate lower than $0.3 \mathrm{C}$ of $\mathrm{CC}-\mathrm{CV}$ strategy, the charging capacity of multistage $\mathrm{CC}-\mathrm{CV}$ strategy is higher than that of CC-CV strategy.

Figure 15 shows the SOC curves of different charging strategies at $0^{\circ} \mathrm{C}$. The charging periods of CC-CV, twostage $\mathrm{CC}-\mathrm{CV}$, and multistage $\mathrm{CC}-\mathrm{CV}$ charging strategies 


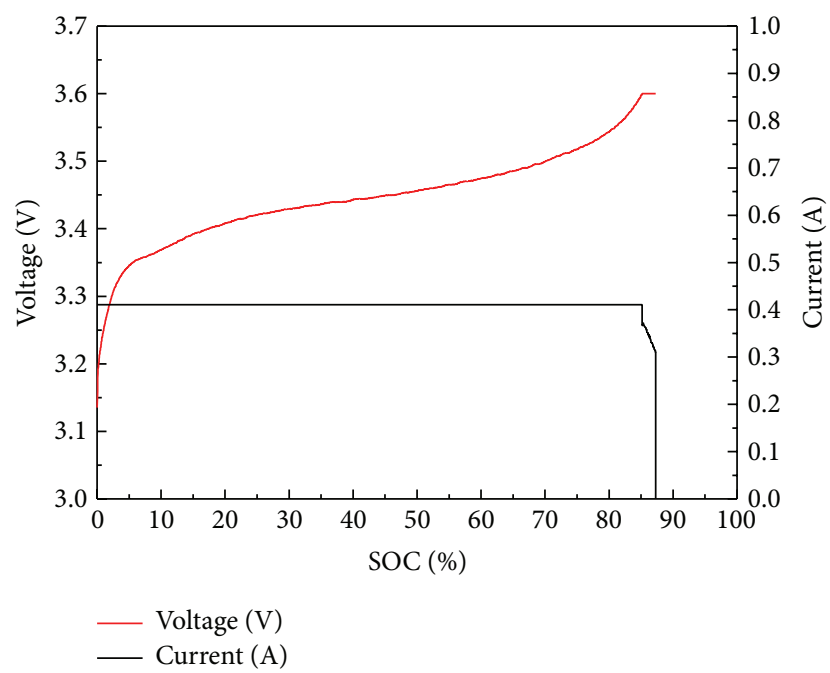

Figure 12: Charging curves of CC-CV strategy at $0^{\circ} \mathrm{C}$.

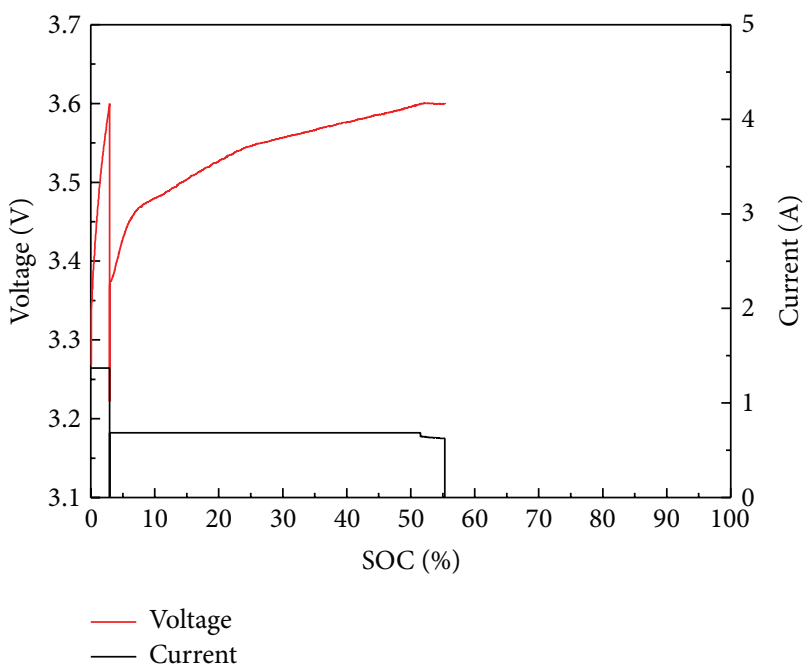

Figure 13: Charging curves of two-stage CC-CV strategy at $0^{\circ} \mathrm{C}$.

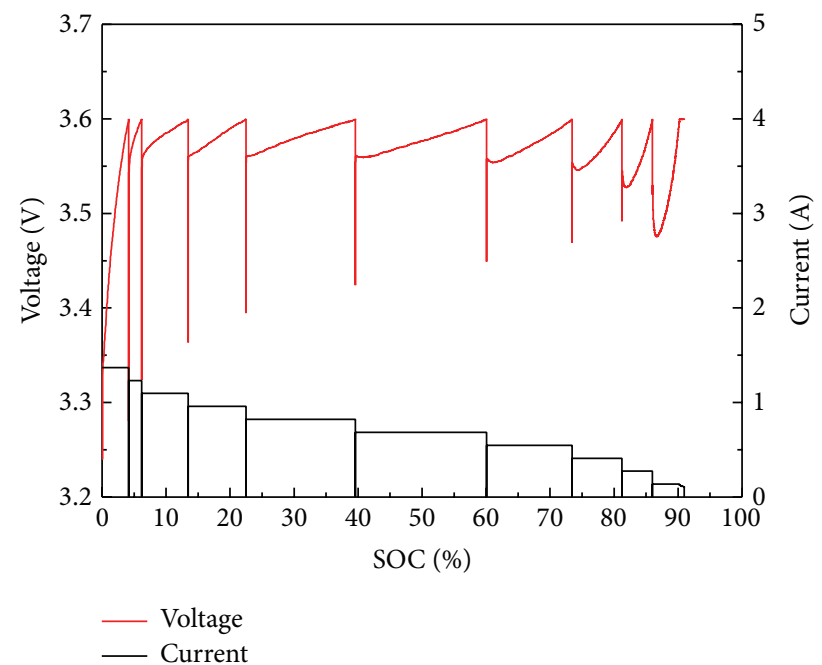

FIGURE 14: Charging curves of multistage CC-CV strategy at $0^{\circ} \mathrm{C}$.

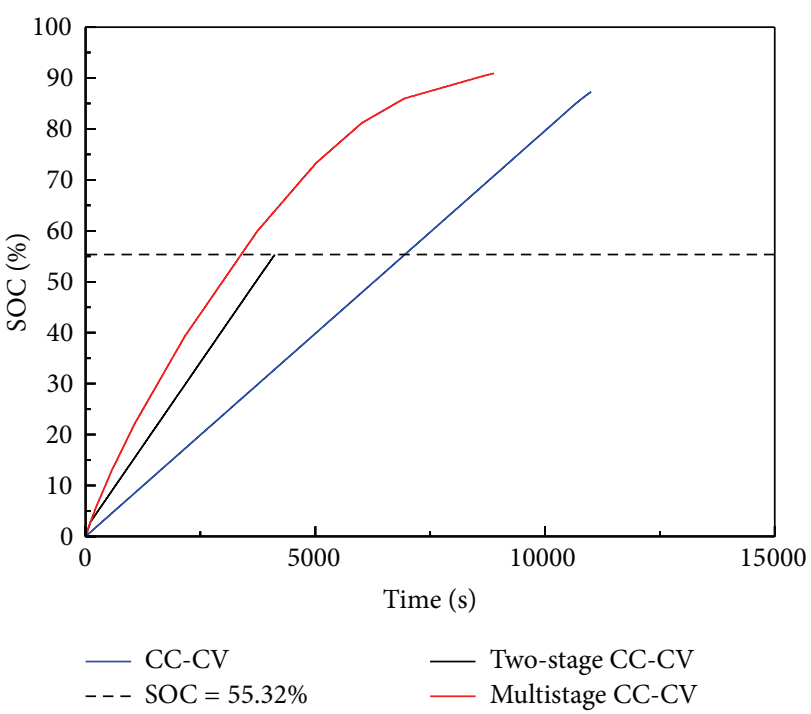

FIGURE 15: SOC curves of different charging strategies at $0^{\circ} \mathrm{C}$.

are $183.4 \mathrm{~min}, 68.7 \mathrm{~min}$, and $148 \mathrm{~min}$. The curve tendency of multistage $\mathrm{CC}-\mathrm{CV}$ charging strategy shows the obvious capacity increasing speed, although the speed is slowed down for the current decrease at later period. As the dotted line shows, the charging period of multistage CC-CV is shorter than that of two-stage CC-CV strategy with the same charging SOC of $55.32 \%$. The multistage CC-CV still has the maximum charging capacity and minimum charging period at $0^{\circ} \mathrm{C}$.

5.3. Different Charging Strategy Analysis at $-10^{\circ} \mathrm{C}$. Figures $16-$ 18 show the terminal voltage curves with different charging strategies at $-10^{\circ} \mathrm{C}$. The terminal voltage of CC-CV strategy reaches cut-off voltage at SOC point of $48.67 \%$. The terminal voltage of the first stage of two-stage CC-CV strategy increases straightly towards the cut-off voltage and the second stage only extends the SOC to $32.26 \%$. All the terminal voltages of charging current at $1 \mathrm{C}-0.6 \mathrm{C}$ of multistage CCCV strategy increase rapidly to the cut-off voltage with SOC growth less than $10 \%$. The terminal voltages of charging current at $0.5 \mathrm{C}-0.1 \mathrm{C}$ increase slower with near $75 \%$ of SOC growth. All the terminal voltage curves indicate that the voltage increases faster at the lower temperature and higher charging current rate.

The charging result at $-10^{\circ} \mathrm{C}$ shows that the capacities of $\mathrm{CC}-\mathrm{CV}$, two-stage $\mathrm{CC}-\mathrm{CV}$, and multistage $\mathrm{CC}-\mathrm{CV}$ charging strategies are $0.664 \mathrm{Ah}, 0.442 \mathrm{Ah}$, and $1.169 \mathrm{Ah}$, respectively. Compared with the charging result at $25^{\circ} \mathrm{C}$, the charging capacities of CC-CV, two-stage CC-CV, and multistage CCCV charging strategies decrease by $47.08 \%, 62.56 \%$, and $14.53 \%$, respectively. It can be indicated that the charging capacity of CC-CV decreases badly and the first stage of two-stage CC-CV strategy oppositely becomes the capacity limit. The multistage CC-CV strategy can keep the charging capacity beyond $80 \%$ even at $-10^{\circ} \mathrm{C}$.

Figure 19 shows SOC curves of different charging strategies at $-10^{\circ} \mathrm{C}$, and the charging periods of CC-CV, two-stage 


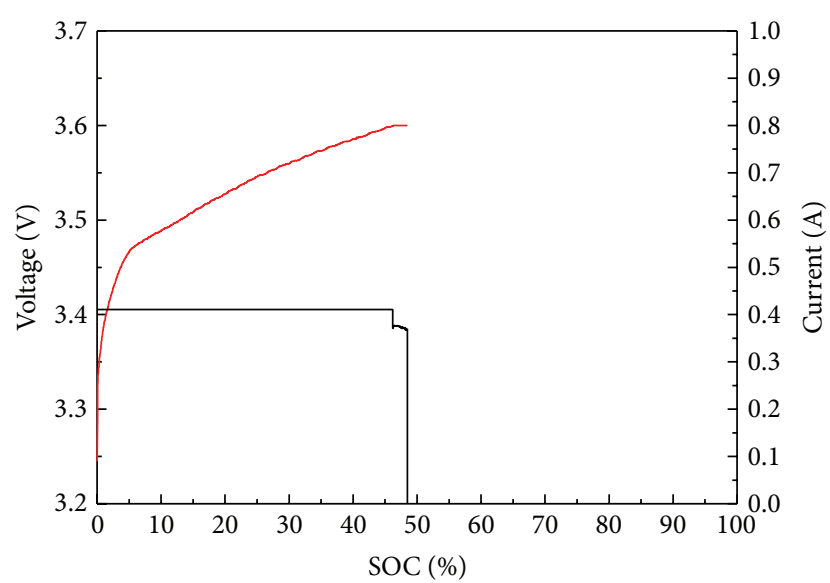

- Voltage

- Current

FIGURE 16: Charging curves of CC-CV strategy at $-10^{\circ} \mathrm{C}$.

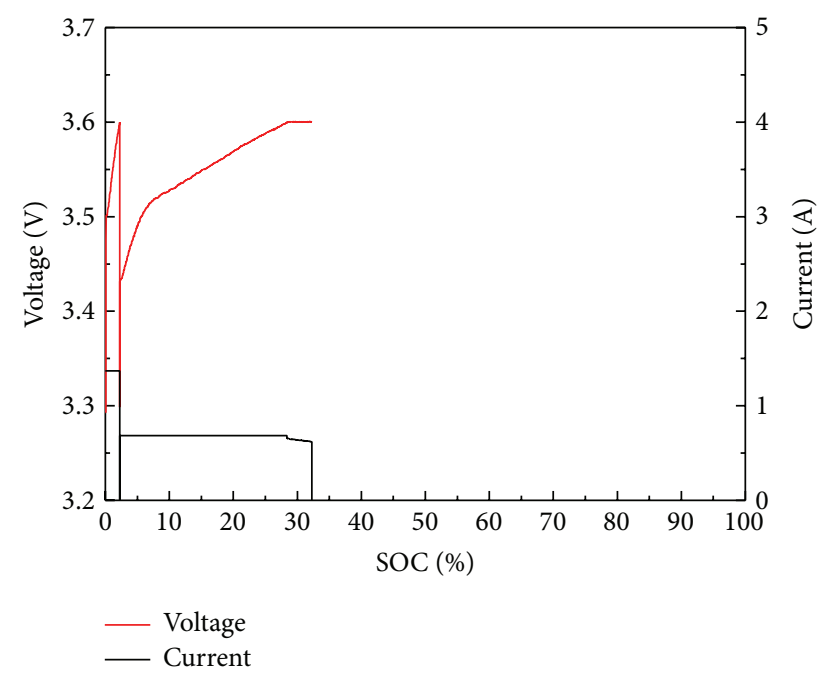

FIgURE 17: Charging curves of two-stage CC-CV strategy at $-10^{\circ} \mathrm{C}$.

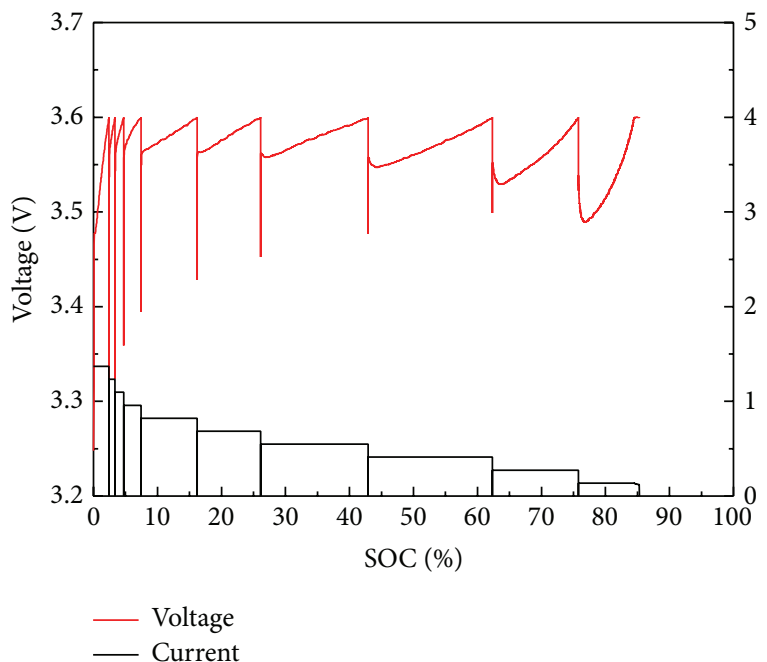

FIGURE 18: Charging curves of multistage CC-CV strategy at $-10^{\circ} \mathrm{C}$.

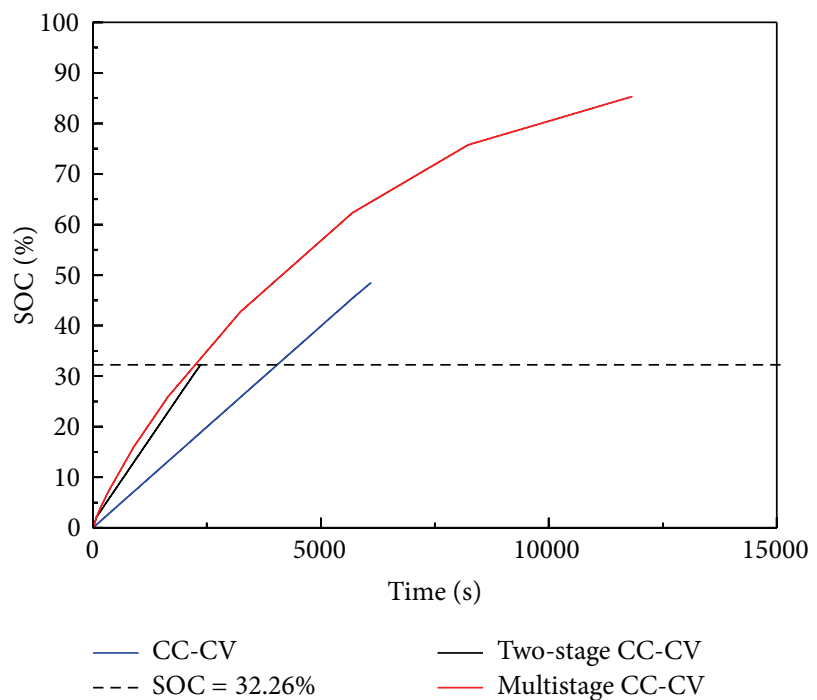

FIGURE 19: SOC curves of different charging strategies at $-10^{\circ} \mathrm{C}$.

CC-CV, and multistage CC-CV charging strategies are $101.7 \mathrm{~min}, 39.38 \mathrm{~min}$, and $197.1 \mathrm{~min}$, respectively. The curve of two-stage CC-CV charging strategy shows the obvious difficulty of capacity increasing at such temperature. Although the terminal voltage increasing slope of two-stage CC-CV strategy is close to that of multistage CC-CV strategy, the charging capacity is significantly different. The comparison of the SOC curves shows that the charging period of multistage CC-CV strategy is still the shortest at the same SOC point. The multistage CC-CV still has maximum charging capacity at $-10^{\circ} \mathrm{C}$

5.4. Analysis of Multistage CC-CV Strategy. Figure 20 shows the capacity curves of different charging current rates of multistage CC-CV strategy at different temperature, and the high charging capacity corresponding charging current rate decreases with temperature decreasing. The charging capacity of $1 \mathrm{C}$ is $1.162 \mathrm{Ah}$, beyond $80 \%$ of battery capacity, and the other charging rates only need to recover the rest of capacity at $25^{\circ} \mathrm{C}$. While the high charging rate does not work well with temperature decreasing, the charging current rate with the maximum charging capacity of $0.28 \mathrm{Ah}$ is $0.5 \mathrm{C}$ at $0^{\circ} \mathrm{C}$. The charging current rate with the maximum charging capacity of $0.266 \mathrm{Ah}$ is $0.3 \mathrm{C}$ at $-10^{\circ} \mathrm{C}$. The main capacity is charged with a range of charging current rates at low temperature. The multistage CC-CV can automatically select the optimal charging current rate for two reasons. (1) The cut-off voltage limit can stop the charging stage of the not optimal charging current rate. (2) The multistage has ten charging current rates from the maximum $1 \mathrm{C}$ to the minimum $0.1 \mathrm{C}$ ensuring the charging demands at different temperature points. The multistage $\mathrm{CC}-\mathrm{CV}$ strategy is a wide temperature range charging strategy that keeps high charging capacity and low charging period.

\section{Conclusion}

It can be seen from the presentation above that the charging capacity of the CC-CV strategy can be only $48.47 \%$ of the 


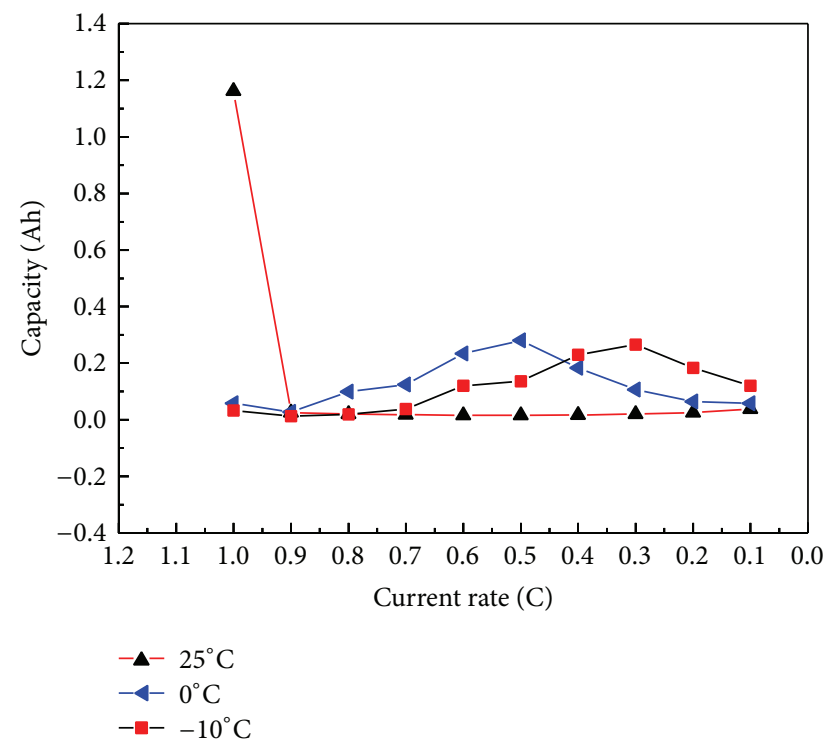

FIgURE 20: Capacity curves of different charging current rates of multistage $\mathrm{CC}-\mathrm{CV}$ strategy at different temperature.

normal capacity at $-10^{\circ} \mathrm{C}$. The charging process is analyzed by electrochemical Li-ion battery model and first-order $R C$ equivalent circuit model. The increase in internal resistance is the main limitation of charging capacity at low temperature. The proposed multistage CC-CV strategy can extend the constant current charging process to obtain a larger capacity by decreasing the charging rate when the terminal voltage reaches the cut-off voltage. Experimental results indicate that the charging capacities with multistage CC-CV strategy at $25^{\circ} \mathrm{C}, 0^{\circ} \mathrm{C}$, and $-10^{\circ} \mathrm{C}$ are $1.368 \mathrm{Ah}, 1.246 \mathrm{Ah}$, and $1.169 \mathrm{Ah}$, respectively. Compared with CC-CV and two-stage CC-CV strategies, the multistage CC-CV strategy has the largest charging capacities and the shortest charging periods at the target temperatures.

\section{Conflict of Interests}

The authors declare that there is no conflict of interests regarding the publication of this paper.

\section{Acknowledgment}

This work is supported by National Natural Science Foundation (NNSF) of China (Grant no. 51105220).

\section{References}

[1] H. Zhang, X. Zhang, and J. Wang, "Robust gain-scheduling energy-to-peak control of vehicle lateral dynamics stabilization," Vehicle System Dynamics, no. 52, pp. 309-340, 2014.

[2] H. Zhang and J. Wang, "Vehicle lateral dynamics control through AFS/DYC and robust gain-scheduling approach," IEEE Transactions on Vehicular Technology, no. 19, 2015.

[3] F. Meng, H. Zhang, D. Cao, and H. Chen, "System modeling and pressure control of a clutch actuator for heavy-duty automatic transmission systems," IEEE Transactions on Vehicular Technology, vol. 99, pp. 1-9, 2015.

[4] D. Ansean, M. Gonzalez, M. V. Garcia, C. J. Viera, C. J. Anton, and C. Blanco, "Evaluation of $\mathrm{LiFePO}_{4}$ batteries for electric vehicle applications," IEEE Transactions on Industry Applications, vol. 2, pp. 1855-1863, 2015.

[5] J. Fan and S. Tan, "Studies on charging lithium-ion cells at low temperatures," Journal of the Electrochemical Society, vol. 153, no. 6, pp. A1081-A1092, 2006.

[6] H.-S. Song, J.-B. Jeong, B.-H. Lee et al., "Experimental study on the effects of pre-heating a battery in a low-temperature environment," in Proceedings of the IEEE Vehicle Power and Propulsion Conference (VPPC '12), pp. 1198-1201, IEEE, Seoul, Republic of Korea, October 2012.

[7] L. Liao, P. Zuo, Y. Ma et al., "Effects of temperature on charge/discharge behaviors of $\mathrm{LiFePO}_{4}$ cathode for Li-ion batteries," Electrochimica Acta, vol. 60, pp. 269-273, 2012.

[8] T. Ikeya, N. Sawada, J.-I. Murakami et al., "Multi-step constantcurrent charging method for an electric vehicle nickel/metal hydride battery with high-energy efficiency and long cycle life," Journal of Power Sources, vol. 105, no. 1, pp. 6-12, 2002.

[9] Y. Gao, C. Zhang, Q. Liu, Y. Jiang, W. Ma, and Y. Mu, "An optimal charging strategy of lithium-ion batteries based on polarization and temperature rise," in Proceedings of the IEEE Conference and Expo Transportation Electrification Asia-Pacific (ITEC AsiaPacific '14), pp. 1-6, IEEE, Beijing, China, September 2014.

[10] L.-R. Chen, "Design of duty-varied voltage pulse charger for improving Li-ion battery-charging response," IEEE Transactions on Industrial Electronics, vol. 56, no. 2, pp. 480-487, 2009.

[11] S. J. Huang, B. G. Huang, and F. S. Pai, "Fast charge strategy based on the characterization and evaluation of $\mathrm{LiFePO}_{4}$ batteries," IEEE Transactions on Power Electronics, vol. 28, no. 4, pp. 1555-1562, 2013.

[12] Y.-H. Liu, J.-H. Teng, and Y.-C. Lin, "Search for an optimal rapid charging pattern for lithium-ion batteries using Ant Colony System algorithm," IEEE Transactions on Industrial Electronics, vol. 52, no. 5, pp. 1328-1336, 2005.

[13] Y.-H. Liu and Y.-F. Luo, "Search for an optimal rapid-charging pattern for Li-ion batteries using the Taguchi approach," IEEE Transactions on Industrial Electronics, vol. 57, no. 12, pp. $3963-$ 3971, 2010.

[14] J. Jiang, C. Zhang, J. Wen, W. Zhang, and S. M. Sharkh, "An optimal charging method for Li-ion batteries using a fuzzy-control approach based on polarization properties," IEEE Transactions on Vehicular Technology, vol. 62, no. 7, pp. 30003009, 2013.

[15] H. J. Ruan, J. C. Jiang, B. X. Sun, N. N. Wu, W. Shi, and Y. R. Zhang, "Stepwise segmented charging technique for lithiumion battery to induce thermal management by low-temperature internal heating," in Proceedings of the IEEE Transportation Electrification Conference and Expo (ITEC '14), Beijing, China, September 2014.

[16] X. W. Zhao, G. Y. Zhang, L. Yang, J. X. Qiang, and Z. Q. Chen, "A new charging mode of Li-ion batteries with $\mathrm{LiFePO}_{4} / \mathrm{C}$ composites under low temperature," Journal of Thermal Analysis and Calorimetry, vol. 104, no. 2, pp. 561-567, 2011.

[17] D. Anseán, M. González, J. C. Viera, V. M. García, C. Blanco, and M. Valledor, "Fast charging technique for high power lithium iron phosphate batteries: a cycle life analysis," Journal of Power Sources, vol. 239, pp. 9-15, 2013. 
[18] G. Hunt and C. Motloch, Freedom Car Battery Test Manual for Power-Assist Hybrid Electric Vehicles, Idaho National Engineering and Environmental Laboratory (INEEL), Idaho Falls, Idaho, USA, 2003.

[19] M. Doyle, J. Newman, A. S. Gozdz, C. N. Schmutz, and J.-M. Tarascon, "Comparison of modeling predictions with experimental data from plastic lithium ion cells," Journal of the Electrochemical Society, vol. 143, no. 6, pp. 1890-1903, 1996.

[20] M. Xu, Z. Q. Zhang, X. Wang, L. Jia, and L. X. Yang, "A pseudo three-dimensional electrochemical-thermal model of a prismatic $\mathrm{LiFePO}_{4}$ battery during discharge process," Energy, vol. 80, pp. 303-317, 2015.

[21] B. Wu, V. Yufit, M. Marinescu, G. J. Offer, R. F. MartinezBotas, and N. P. Brandon, "Coupled thermal-electrochemical modelling of uneven heat generation in lithium-ion battery packs," Journal of Power Sources, vol. 243, pp. 544-554, 2013.

[22] J. Kim, S. Lee, and B. H. Cho, "Complementary cooperation algorithm based on DEKF combined with pattern recognition for SOC/capacity estimation and SOH prediction," IEEE Transactions on Power Electronics, vol. 27, no. 1, pp. 436-451, 2012.

[23] J. Kim, J. Shin, C. Chun, and B. H. Cho, "Stable configuration of a $\mathrm{Li}$-ion series battery pack based on a screening process for improved voltage/SOC balancing," IEEE Transactions on Power Electronics, vol. 27, no. 1, pp. 411-424, 2012. 


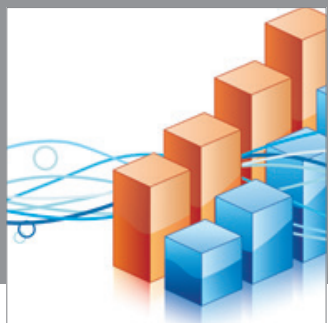

Advances in

Operations Research

mansans

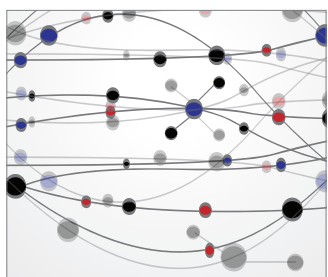

The Scientific World Journal
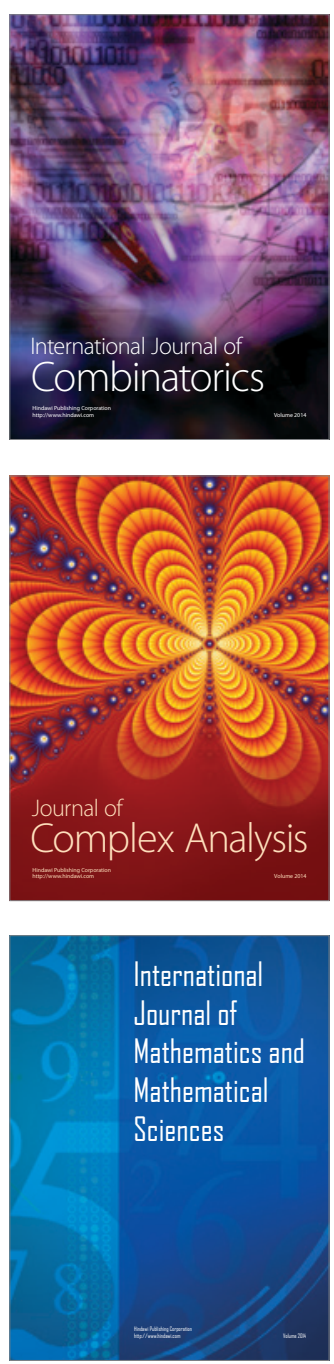
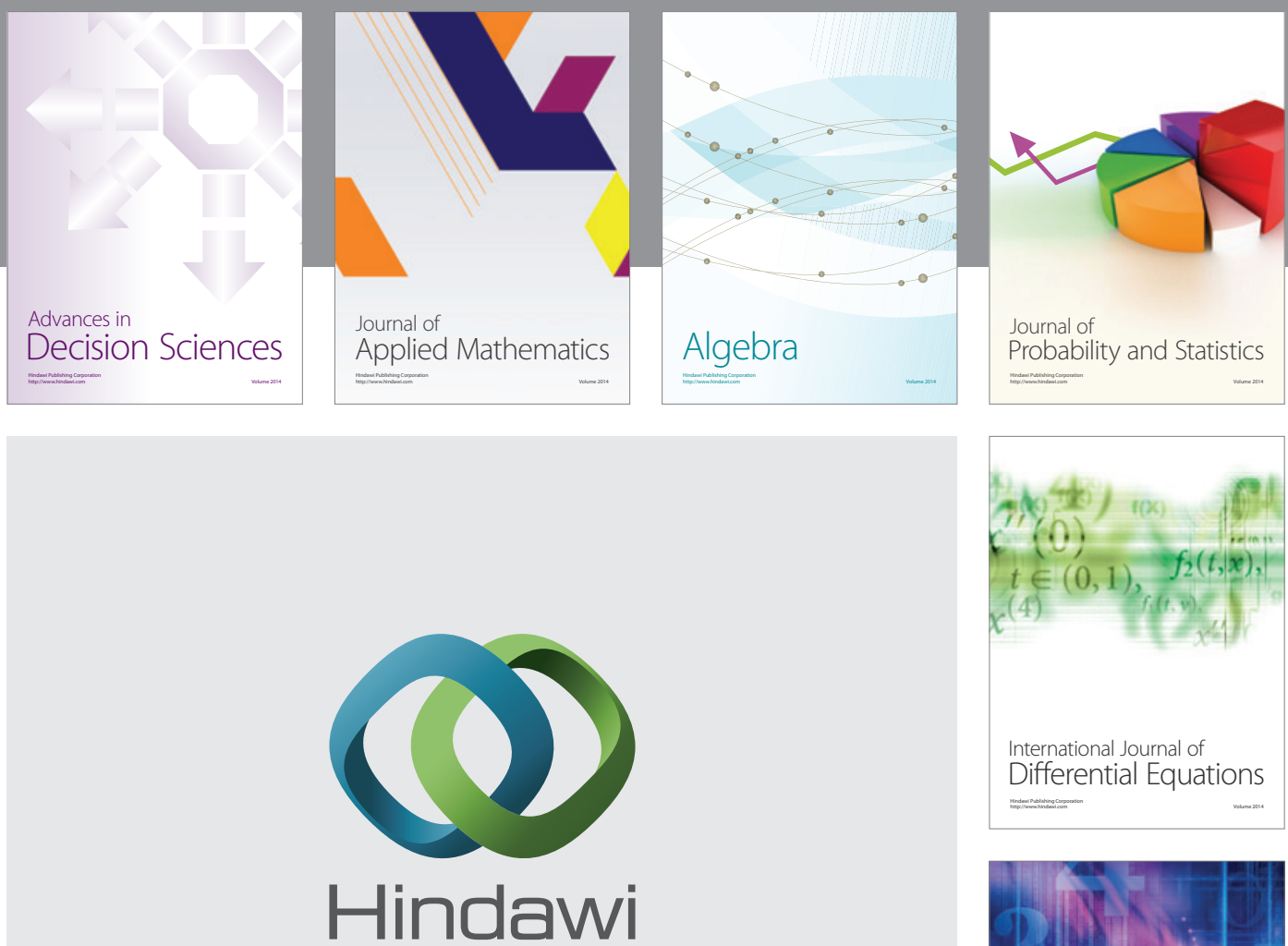

Submit your manuscripts at http://www.hindawi.com
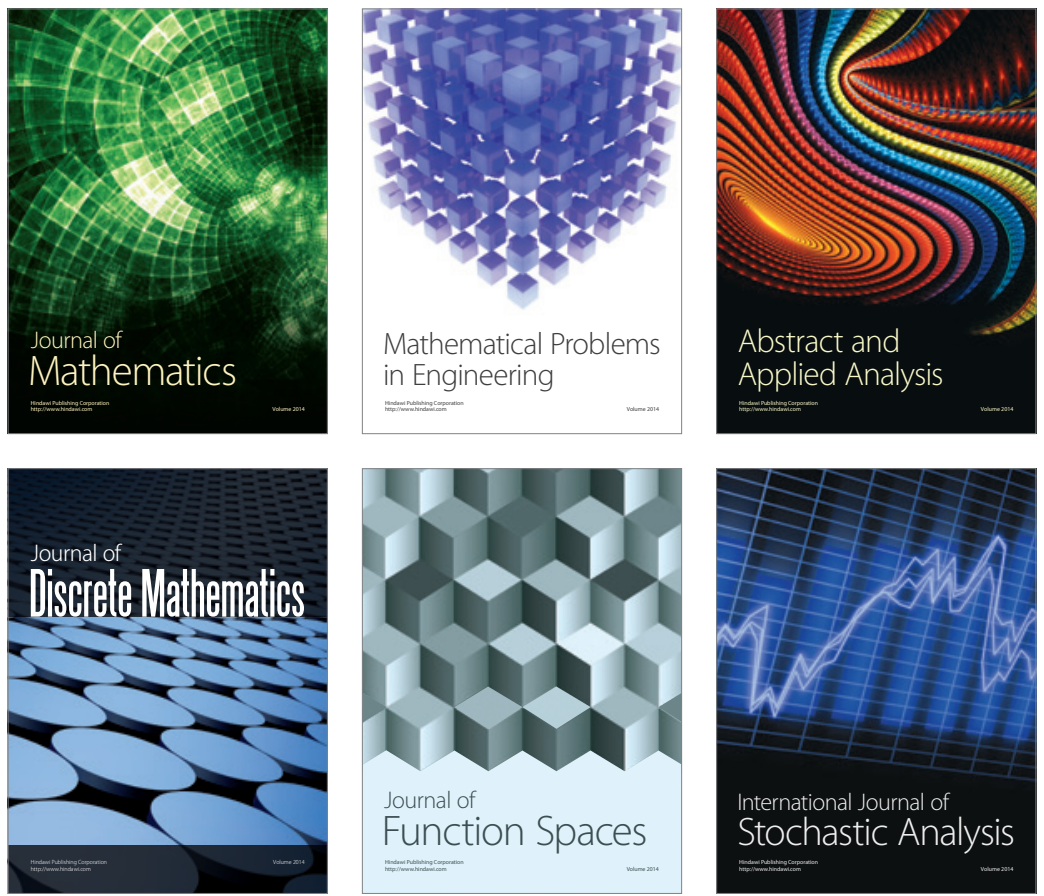

Journal of

Function Spaces

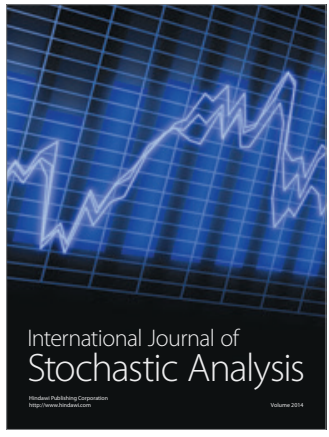

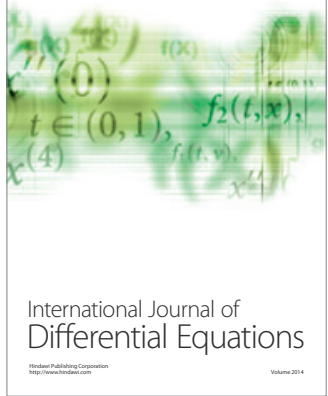
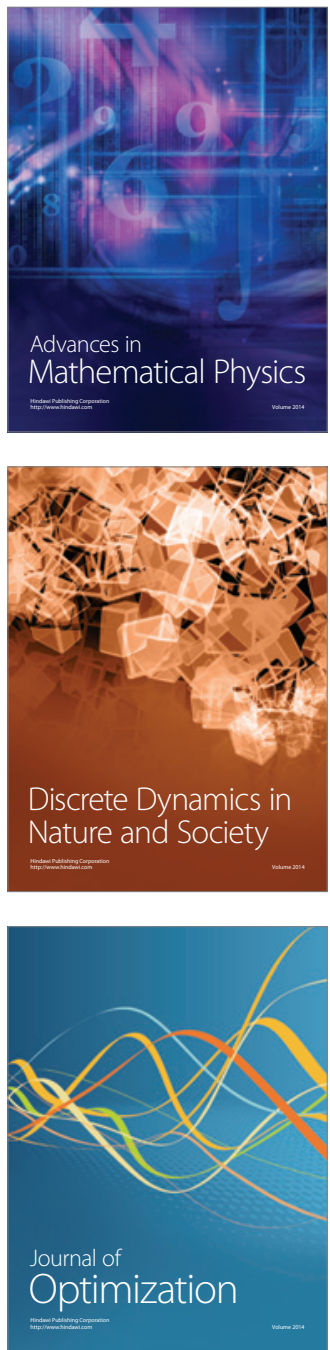